\title{
Cartelization Through Buyer Groups
}

\author{
Chris Doyle * \\ Martijn A. Han **
}

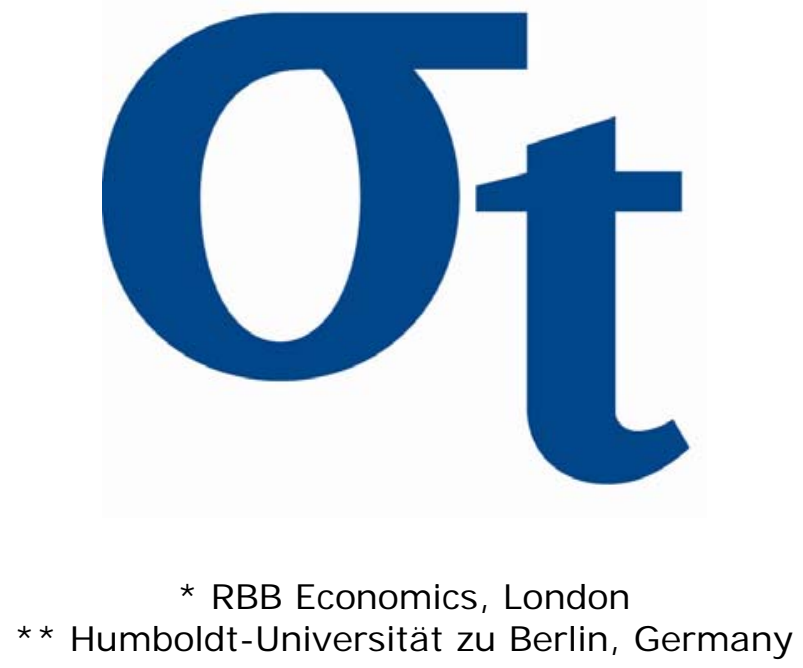

$\frac{v}{\alpha}$

This research was supported by the Deutsche Forschungsgemeinschaft through the SFB 649 "Economic Risk".

http://sfb649. wiwi.hu-berlin. de ISSN 1860-5664 


\title{
Cartelization Through Buyer Groups*
}

\author{
Chris Doyle \\ RBB Economics, London \\ chris.doyle@rbbecon.com
}

\author{
Martijn A. Han \\ Institute for Microeconomic Theory, \\ Humboldt Universität zu Berlin \\ martijn.alexander.han@hu-berlin.de
}

October 2, 2012

\begin{abstract}
Retailers may enjoy stable cartel rents in their output market through the formation of a buyer group in their input market. A buyer group allows retailers to credibly commit to increased input prices, which serve to reduce combined final output to the monopoly level; increased input costs are then refunded from suppliers to retailers through slotting allowances or rebates. The stability of such an "implied cartel" depends on the retailers' incentives to secretly source from a supplier outside of the buyer group arrangement at lower input prices. Cheating is limited if retailers sign exclusive dealing or minimum purchase provisions. We discuss the relevancy of our findings for antitrust policy.
\end{abstract}

Keywords: buyer groups, collusion, exclusive dealing, minimum purchase clauses, rebates.

JEL codes: K21, L13, L41, L42.

*This paper was written during our PhD track at the London School of Economics (Chris Doyle) and the Amsterdam Center for Law \& Economics of the University of Amsterdam and a research visit to the Toulouse School of Economics (Martijn Han). We are grateful to these institutions. An earlier version of this paper was part of Martijn's PhD thesis Vertical Relations in Cartel Theory (carteltheory.com), which was awarded the 2012 Concurrences PhD Thesis Award in Paris, February 2012. We thank Charles Angelucci, Mark Armstrong, John Asker, Marie Goppelsröder, John Kwoka, Adrian Majumdar, Alasdair Rutherford, Maarten Pieter Schinkel, and Jeroen van de Ven for constructive discussions and comments. We are also grateful to participants at CLEEN 2009 at TILEC in Tilburg, and the CCP New Researchers Workshop on Cartels and Tacit Collusion 2009 at the University of East Anglia (Norwich), as well as to seminar participants at the U.K. Competition Commission, the Netherlands Competition Authority (NMa), and the University of Amsterdam. This research is supported by the Deutsche Forschungsgemeinschaft via the Collaborative Research Center 649 "Economic Risk". 


\section{Introduction}

Buyer groups are cooperative arrangements between retailers to combine their purchases in input markets. Such groups are wide-spread, especially in the grocery industry. ${ }^{1}$ A common rationale for forming a buyer group is to exercise buyer power (countervailing power) over suppliers, thereby obtaining more favorable contractual terms, such as lower wholesale prices or increased input quality. As such, buyer groups have the potential to improve welfare, because lower input prices may be passed on to consumers. ${ }^{2}$

This paper abstracts away from countervailing power and monopsony motivations and focuses on the stability of a strictly anticompetitive rationale behind the formation of buyer groups in wholesale markets with unobservable contracting. Central sourcing through a buyer group allows retailers to jointly coordinate on wholesale contracts with increased input prices, thereby increasing retail prices all the way up to the monopoly level. Increased input costs are then refunded from suppliers to retailers through slotting allowances, thus allowing retailers to expropriate monopoly profits. ${ }^{3}$ Since buyer groups are not per se illegal, this mechanism may be a smart "cartelization" strategy.

Foros and Kind (2008) have demonstrated the workings of such a mechanism in a static environment. ${ }^{4}$ In a dynamic environment, however, similar to the stability concerns of a standard output market cartel, the stability of an anticompetitive buyer group depends on the ability and incentives of retailers to cheat on the buyer group by secretly signing an additional contract outside of the anticompetitive arrangement at a lower input price. Such a move allows the deviant retailer to

\footnotetext{
${ }^{1}$ See, for example, Dobson and Waterson (1999). Some buyer groups exist within a single market segment such as the Independent Grocers Association (IGA), which is the world's largest voluntary supermarket network with aggregate worldwide retail sales of more than $\$ 21$ billion per year. Other buyer groups extend across different markets; for example, Corporate United covers industries as various as health care, chemicals, telecommunications, defense, and financial services. Its membership employs over 1.2 million people and combined revenues add up to more than $\$ 400$ billion.

${ }^{2}$ Explanations for sources of buyer power include retailers' capacity to integrate backwards (Katz, 1987), to sponsor entry upstream (Inderst and Shaffer, 2007), to thwart collusion by suppliers (Snyder, 1996, 1998), to engage in multiple sourcing (Inderst, 2007), their position as 'gatekeeper' retailers (Majumdar, 2006), explanations related to economic dependancy (OECD, 1998) and buyers' sophistication (Nordemann, 1995).

${ }^{3}$ Shaffer (1991) shows that, if wholesale contracts are observable, retailers may increase their profits above anticompetitive levels without explicit coordination. However, Shaffer's (1991) strategic effect does not allow profits to be raised to the full monopoly level, while it relies on wholesale contracting being observable, which may not always be realistic as wholesale prices are usually not publicly listed and negotiations often take place "behind closed doors".

${ }^{4}$ Similar mechanisms can arise through joint ventures and franchising. Our policy discussion in Section 5 discusses these similarities.
} 
source cheaper inputs, so as to gain a competitive advantage over its rivals in the output market, and is therefore a relevant concern for the stability of the anticompetitive mechanism.

We show that commonly observed vertical restraints - exclusivity provisions and minimum purchase clauses - facilitate the stability of the buyer group. These restraints effectively limit the deviant retailers' ability to source from suppliers outside of the joint agreement. By including such provisions in the jointly negotiated wholesale contracts, retailers credibly tie their own hands, which may allow the buyer group induced monopoly outcome to be stable for all discount factors. Without vertical restraints, the buyer group arrangement can still induce extraction of cartel rents as long as retailers are sufficiently patient. We also argue that the buyer group's stability equals that of standard output market collusion if the ex-ante slotting allowance is instead paid as an ex-post rebate (scheme). Finally, we note that buyer group specific cost savings increase its anticompetitive stability, while consumers actually benefit if the pass-on of cost efficiencies outweighs the collusive effect.

We proceed by discussing related literature in Section 2. Section 3 presents the anticompetitive buyer group arrangement and shows that exclusivity provisions make the "implied cartel" stable for all discount factors. Section 4 investigates its interaction with minimum purchase clauses and rebate schemes, and explores the impact of buyer group specific cost efficiencies. Section 6 concludes by discussing the policy implications of the model.

\section{Related Literature}

Existing explanations for buyer groups include reducing wholesale prices when facing monopolistically competitive suppliers (Mathewson and Winter, 1996), 'managing competition' in healthcare markets (Che and Gale, 1997), strategic commitments to buy on the basis of price alone (Dana, 2003), creating a stronger joint bargaining position (Chae and Heidhues, 2004), and allowing for welfare-enhancing loyalty discounts (Marvel and Yang, 2008). In these papers, the buyer group explicitly affects the competitive process between suppliers and retailers. In contrast, we abstract away from buyer power motivations; the main purpose of the buyer group in our model is to facilitate coordination on the input market that affects the competitive outcome on the output market. Our work most relates to Foros and Kind (2008) and Piccolo (2010); we discuss the differences in turn.

In a dynamic setting, this paper employs an anticompetitive mechanism similar in spirit to that outlined by Shaffer (1991). In a static framework, Foros and Kind (2008) show that a buyer group 
may implement Shaffer's mechanism by making wholesale contracting observable. ${ }^{5}$ Their focus is on the welfare effects of slotting allowances used by buyer groups in a one-shot game, while we focus on the stability of buyer groups using slotting allowances, rebate schemes and other vertical restraints. ${ }^{6}$ We examine the stability of an anticompetitive buyer group in a dynamic environment by constructing an infinitely repeated game similar to models of collusion, while allowing for (i) secret contracting outside of the buyer group arrangement, and (ii) buyer group specific cost efficiencies. The buyer group effectively acts as an 'implicit cartel' facing a stability issue similar to that of an output market cartel.

Complementary to our work, Piccolo (2010) studies the impact of wholesale contracting on an output market cartel and discusses the role of communication between retailers in sustaining such a cartel. He studies a non-standard cartel program and demonstrates how coordination on the input market enhances collusion on the output market, while we show how collusion on the input market alone is sufficient to achieve the monopoly outcome, without firms forming an output cartel and with wholesale contracts being unobservable. Allowing for exclusive dealing contracts, Piccolo shows that the joint monopoly outcome can be more easily sustained, but not for all discount factors as is the case in our model. The reason is that in Piccolo's model collusion takes place on the output market, and therefore deviation also takes place on the output market. In contrast, in our model collusion takes place on the input market, so deviation (on the input market) is fully restricted by exclusive dealing contracts.

The underlying idea of the Shaffer (1991) effect has its roots in the strategic delegation literature. Fershtman and Judd (1987) and Sklivas (1987) are the seminal papers, which show that commitment on a particular incentive scheme for managers allows firms to soften or intensify product market competition. In the same spirit, Shaffer (1991) shows that commitment on increased wholesale prices in the input market allows retailers to soften competition on the output market. ${ }^{7}$ Two assumptions play a key role in the strategic delegation framework: (i) observability of contracts

\footnotetext{
${ }^{5}$ In a setting without a buyer group, Miklós-Thal, Rey and Vergé (2011) show that industry profits can be maximised when retailers make offers to a single supplier provided that contracts are observable and can be sufficiently complex, for example through specifying three-part tariffs incorporating conditional fixed payments.

${ }^{6}$ Dana (2004) also examines the issue of buyer group stability, but in the context of how this impacts on the terms a group is able to secure from suppliers for its members. Specifically, when members can jointly commit to bundle their purchases together to buy exclusively from a single seller, they are generally able to secure lower input prices and hence greater profits than if they are unable to commit in this way.

${ }^{7}$ While Shaffer (1991) assumes that retailers have full bargaining power, Irmen (1998) assumes that suppliers have full bargaining power and finds the same result as Shaffer (1991), but with a positive instead of a negative fixed fee.
} 
and (ii) commitment to contracts. As discussed above, our model does not require observability of contracts. As for the commitment aspect, Rey and Stiglitz (1995) argue that irreversibility of wholesale contracts may be a reasonable assumption, since wholesale prices are usually determined before the price game between retailers takes place; as noted by Foros and Kind (2008), retailers usually do not engage in long-term contracting with consumers, while wholesale contracts are often set for longer periods.

Although we abstract away from countervailing power motivations, our work is closely related to the policy debate surrounding the issue of buyer power, which has been the focus of increased attention from both practitioners and academics. ${ }^{8}$ Therefore, Section 6 of the paper discusses the policy implications of our results, arguing that similar mechanisms are at work with franchising, joint ventures and resale price maintenance. Our model also relates to the exclusive dealing literature as we show that vertical restraints tie the hands of retailers and therefore serve as credible commitment devices for them to adhere to the anticompetitive buyer group arrangement. ${ }^{9}$

\section{Buyer Groups and Exclusive Dealing}

In this section, we describe the game and show that slotting allowance contracts negotiated through buyer groups serve to allow retailers to expropriate the full monopoly rents on the output market. Exclusive dealing provisions ensure that this outcome is stable for all discount factors.

Players Consider an industry consisting of $n$ identical retailers, sourcing from perfectly competitive price-taking suppliers that produce at constant marginal cost $c$. We model suppliers as being perfectly competitive to abstract away from countervailing power and monopsony motivations; that is, retailers extract all wholesale surplus, independent of the existence of a buyer group. ${ }^{10}$ The retailers costlessly transform one unit of input into one unit of output, and face continuously differentiable consumer demand $D(p)$, where $D^{\prime}(p)<0$.

\footnotetext{
${ }^{8}$ Work on buyer power includes, for example, Snyder (1996, 1998), Dobson and Waterson (1997), and Inderst and Wey $(2003,2007)$.

${ }^{9}$ Major works in the exclusive dealing literature include Aghion and Bolton (1987), Rasmusen, Ramseyer and Wiley (1991), Bernheim and Whinston (1998), Segal and Whinston (2000), Fumagalli and Motta (2006), Simpson and Wickelgren (2007) and Abito and Wright (2008).

${ }^{10}$ In Section 5, we argue that buyer power generated through the buyer group actually reinforces our results.
} 
Timing and actions Retailers have the option to form a buyer group, which means that (i) the participating retailers jointly offer take-it-or-leave-it wholesale contracts to suppliers, while (ii) they source their inputs centrally through this buyer group. This allows for monitoring the behavior of each buyer group member.

Firms interact for an infinite number of periods. Each period consists of three stages:

1. Buyer group stage Retailers each individually decide whether to sign up to a buyer group, and are able to condition their participation on other retailers joining.

2. Contracting stage If the buyer group is not established in stage 1 , retailers independently and simultaneously offer take-it-or-leave-it contracts to suppliers. If a buyer group is established, then its members jointly offer take-it-or-leave-it contracts with one or more suppliers with the objective of maximising the joint profits of the buyer group members.

The buyer group members also have the possibility to (secretly) make take-it-or-leave-it contractual offers outside of the group arrangement. Contracting takes the form of each retailer $i$, or the buyer group on behalf of all retailers, making a take-it-or-leave-it two-part tariff offer to a supplier, consisting of a linear element $w_{i}$ and a fixed fee element $\tau_{i}$. The supplier accepts or rejects the offer. $^{11}$

3. Competition stage Given prevailing wholesale contracts, retailers act non-collusively in their output market; they compete by simultaneously setting either quantities or prices.

Information All contracts negotiated outside of the buyer group arrangement are unobservable to rival retailers. That is, contracts are private information if (i) no buyer group is established in the first place, or (ii) a buyer group is established, but a buyer group member decides to negotiate an additional contract outside of the buyer group arrangement. However, both the contracts negotiated through the buyer group, and the volume of inputs sourced through the group, are observable to all buyer group members after the competition stage. ${ }^{12}$

\footnotetext{
${ }^{11}$ Since the upstream industry is perfectly competitive, retailers extract all of the surplus independent of the bargaining framework. That is, we could equally have suppliers making take-it-or-leave-it offers to retailers: equilibrium contracts would be the same, since suppliers have no bargaining power.

${ }^{12}$ We take the conservative approach that input volumes through buyer group contracts are observed at the end of the period. Otherwise, the buyer group would allow for immediate monitoring and punishment of a deviant retailer within the same period. This would increase buyer group stability and, thus, reinforces our anticompetitive mechanism. However, the anticompetitive buyer group emerges already solely through the joint writing of "smart" input contracts, and does not rely on the immediate monitoring of wholesale market activities. We thank an anonymous referee for this point.
} 
The game on the output market is characterized by perfect monitoring, i.e., quantities and prices, are observable by all retailers.

Payoffs If retailer $i$ 's offer is accepted by a supplier, the fixed amount $\tau_{i}$ is paid immediately after the contracting stage, while the variable amount $q_{i} w_{i}$ is paid immediately after the competition stage, where $q_{i}$ is the quantity sourced by retailer $i$. Payoffs are discounted with factor $\delta$.

Given actual prevailing wholesale contracts, we make the following assumptions on each retailer $i$ 's profit function $\pi_{i}(\mathbf{w}, \boldsymbol{\tau})$,

$$
\begin{aligned}
& \frac{\partial \pi_{i}(\mathbf{w}, \boldsymbol{\tau})}{\partial w_{i}} \leq 0, \frac{\partial \pi_{i}(\mathbf{w}, \boldsymbol{\tau})}{\partial w_{j}} \geq 0 \\
& \frac{\partial \pi_{i}(\mathbf{w}, \boldsymbol{\tau})}{\partial \tau_{i}}<0, \frac{\partial \pi_{i}(\mathbf{w}, \boldsymbol{\tau})}{\partial \tau_{j}}=0, \forall i, \forall j \neq i
\end{aligned}
$$

where $\mathbf{w}=\left[w_{1}, \ldots, w_{n}\right]$ and $\boldsymbol{\tau}=\left[\tau_{1}, \ldots, \tau_{n}\right]$ are the vectors of linear and fixed elements of actual prevailing wholesale contracts, respectively. Assumptions (1) guarantee that a retailer's profit weakly decreases (increases) with its own (rival's) variable input costs. Assumptions (2) state that a retailer's profits decrease (do not change) with its own (rival's) fixed input costs. Note that, given prevailing wholesale contracts, retailers' competitive behavior on the output market depends on marginal input costs only, because fixed input costs are sunk.

Equilibrium concept We solve for the symmetric subgame perfect equilibrium of the game. First, in the contracting stage we solve for wholesale contracts that maximise the buyer group members' joint profits when they (Nash) compete in the competition stage. Second, if such a strategy is unstable due to the threat of buyer group members deviating and secretly sourcing outside of the buyer group arrangement, we solve for the critical discount factor such that the maximum joint profit (monopoly profit) is supported by grim-trigger punishment in the form of reversion to Nash behavior.

We focus on the symmetric equilibrium in which all retailers join the buyer group to collude on the monopoly outcome. This is conceptually equivalent to standard output market collusion in which all retailers join the collusive agreement and coordinate on the monopoly outcome, which is the standard benchmark in the literature on cartels and collusion. This allows us to make a meaningful comparison between the stability of an "implied cartel" on the input market and the stability of an output market cartel. 


\subsection{No Buyer Group}

When none of the retailers sign up to the buyer group, each retailer individually and unobservably negotiates with perfectly competitive suppliers. Because wholesale contracts are secret, in the contracting stage, each retailer prefers to write a contract with variable costs as low as possible, so as to secure an optimal competitive position vis-a-vis rival retailers in the competition stage. This leads to $w_{i}=c$ for every $i{ }^{13}$ That is, by setting the linear element at the suppliers' marginal cost $c$, retailers overcome the double marginalisation problem. Each retailer sets the fixed fee at zero, so as to keep all of the profits, resulting in suppliers earning (perfectly) competitive profits and each retailer earning competitive profits $\pi^{c} \equiv \pi_{i}\left(\mathbf{w}^{c}, \boldsymbol{\tau}^{c}\right)$ in each period, where $\mathbf{w}^{c}=[c, \ldots, c]$ and $\tau^{c}=[0, \ldots, 0]$, i.e.

$$
\left(w_{i}^{c}, \tau_{i}^{c}\right)=(c, 0)
$$

for every retailer $i \in\{1, \ldots, n\}$, where superscript 'c' represents the competitive case.

\subsection{Fully Stable Buyer Group}

Given the set-up of the game, the optimal symmetric strategy to form a buyer group is that retailer $i$ joins the buyer group in a given period if and only if $(i)$ all rival retailers $j \neq i$ join the buyer group in that period, (ii) all rival retailers joined the buyer group in all previous periods, and (iii) none of the rival retailers negotiated contracts outside of the buyer group arrangement in previous periods. Hence, if not all of these conditions are met, the buyer groups is not formed. This symmetric strategy ensures that all retailers indeed join the group, because no buyer group is formed when one or more retailers decide not to join, which would result in competitive profits with contracts $\left(w_{i}^{c}, \tau_{i}^{c}\right)=(c, 0)$ as described in the previous subsection.

Suppose that retailers are able to sign contracts containing exclusive dealing clauses, which specify that retailers may only source through the current contract and are prohibited from sourcing through alternative suppliers. We assume that such contracts are legally binding and credibly enforceable, such that breaking the exclusive dealing clause leads to the deviant retailer facing an expected fine large enough to deter a retailer from such a deviation.

Denote by $Q^{m}$ and $p^{m}$ the retailers' total monopoly quantity and monopoly price, respectively.

\footnotetext{
${ }^{13}$ O'Brien and Shaffer (1992) show that, with unobservable contracting, even a sole supplier making take-it-or-leaveit offers to retailers may be unable to achieve the vertically integrated joint profit maximizing outcome.
} 
Proposition 1 All retailers join the buyer group and jointly negotiate the exclusive dealing contract $\left(w^{m}, \tau^{m}\right)$, where $w^{m}$ and $\tau^{m}$ are such that, for every retailer $i$,

$$
\begin{aligned}
q_{i}\left(\mathbf{w}^{m}\right) & =q^{m} \text { in the case of quantity competition among retailers, or } \\
p_{i}\left(\mathbf{w}^{m}\right) & =p^{m} \text { in the case of price competition among retailers; and } \\
\tau^{m} & =-\left(w^{m}-c\right) q^{m}
\end{aligned}
$$

where $q^{m}=Q^{m} / n$ and $\mathbf{w}^{m}=\left[w^{m}, \ldots, w^{m}\right]$. This contract allows retailers to jointly extract monopoly profits, and is stable against deviation for all discount factors.

Proof. The buyer group consists of all retailers, otherwise the group is not formed in the first place and all retailers would earn competitive profits, as discussed in the first paragraph of Secion 3.2. Its members negotiates wholesale contracts that maximise their joint profits. With quantity or price competition, respectively, this is achieved by solving $(\mathbf{w}, \boldsymbol{\tau})$ from

$$
\begin{aligned}
& \max _{(\mathbf{w}, \boldsymbol{\tau})} \sum_{i=1}^{n} \pi_{i}((\mathbf{w}, \boldsymbol{\tau}))=\max _{(\mathbf{w}, \boldsymbol{\tau})} \sum_{i=1}^{n}\left[q_{i}(\mathbf{w})\left(p(Q(\mathbf{w}))-w_{i}\right)-\tau_{i}\right], \text { or } \\
& \underset{(\mathbf{w}, \boldsymbol{\tau})}{\max } \sum_{i=1}^{n} \pi_{i}((\mathbf{w}, \boldsymbol{\tau}))=\max _{(\mathbf{w}, \boldsymbol{\tau})} \sum_{i=1}^{n}\left[q_{i}(\mathbf{p}(\mathbf{w}))\left(p_{i}(\mathbf{w})-w_{i}\right)-\tau_{i}\right],
\end{aligned}
$$

such that suppliers do not earn negative profits.

In the case of quantity (price) competition, industry profits are then maximised if wholesale contracts specify linear elements $w^{m}$ that induce the downstream monopoly output (price). That is, $q_{i}\left(\mathbf{w}^{m}\right)=Q^{m} / n$ in case of quantity competition, and $p_{i}\left(\mathbf{w}^{m}\right)=p^{m}$ in case of price competition, for every retailer $i$. The revenue earned by each active supplier from each retailer is refunded via the fixed fee, $\tau^{m}=-\left(w^{m}-c\right) q^{m}$. Including an exclusive dealing provision prevents retailers from deviating by signing an additional contract outside of the buyer group, which makes the arrangement stable for all discount factors.

The buyer group thus allows retailers to jointly commit to higher wholesale tariffs $w^{m}>c$, which dampens competition at the retail level, resulting in joint monopoly profits. The revenue earned by each active supplier $\left(w^{m}-c\right) q^{m}$ from each retailer is refunded through a negative fixed fee $\tau^{m}$, which corresponds to a slotting allowance. ${ }^{14}$ Since the slotting allowance is a fixed fee, it

\footnotetext{
${ }^{14}$ An analysis of slotting allowances is presented in Shaffer (1991) and Marx and Shaffer (2007), who describe the practice as widespread across many industries, particularly grocery retailing. The Federal Trade Commission (2003) conducted an analysis of slotting allowances in this industry and found them to be common practice.
} 
is a contractual sunk cost for the suppliers and a contractual sunk income for the retailers; thus, its size is independent on the number of inputs sourced and does not affect the retailers' behavior. Therefore, this mechanism allows retailers to jointly expropriate monopoly profits by coordinating through a buyer group on the input market, without engaging in per se illegal collusion in the output market.

Note that such an outcome is not possible without the presence of the buyer group. Retailers would then prefer an unobservable wholesale contract specifying a wholesale tariff $c$, so as to be able to increase output (or decrease price) at the expense of rivals' profits. The buyer group serves to prevent such opportunistic behavior by allowing buyer group members to jointly commit to wholesale tariff $w^{m}$. This contract can be with one or several suppliers; the key point is that the contract(s) is (are) negotiated jointly by all group members. ${ }^{15}$

Although retailers have all of the bargaining power, they choose to sign exclusive deals that bind them to their suppliers. This is in contrast with another type of exclusive deal observed in practice, i.e., one in which retailers use their negotiation power to bind their suppliers solely to them. Instead, in our model retailers use their bargaining power to tie their own hands. The intuition is that the exclusive deal serves as a commitment device for retailers to not deviate in the input market, resulting in the stabilisation of the coordinated input market arrangement. Not only retailers prefer exclusivity provisions, suppliers also prefer them: the exclusivity provision is a means of guaranteeing that suppliers can recoup their expenditure on slotting allowances. Without such a clause, a supplier cannot legally prevent a retailer from sourcing from another supplier outside of the buyer group arrangement.

An exclusive deal set up by a buyer group may attract the attention of competition authorities. However, the European Commission's (EC) guidelines on horizontal cooperation agreements (2001) recognise that:

"An obligation to buy exclusively through the cooperation can in certain cases be indispensable to achieve the necessary volume for the realisation of economies of scale."

Hence, buyer groups using exclusive deals in their contracts are not necessarily illegal, and can

\footnotetext{
${ }^{15}$ More generally, in an infinitely repeated game, one could also think of an anticompetitive mechanism in which suppliers could develop a reputation of not agreeing with unit wholesale prices lower than $w^{m}$. Retailers could punish a supplier giving discounts by not sourcing from that supplier in future periods. As our game models suppliers as being perfectly competitive, they earn zero profits anyway, and such punishment is irrelevant; the mechanism breaks down. We thank an anonymous referee for this point.
} 
actually be falsely defended using the argument that they are required to allow the group to achieve sufficient scale.

\section{Buyer Groups, Minimum Purchase Clauses and Rebate Schemes}

We now relax the assumption that retailers are able to sign exclusive deals with suppliers, and examine the stability of the buyer group arrangement when this is not the case. Instead, we allow contracts to specify a minimum order size that the retailer in question is legally obliged to purchase from the relevant supplier. Such minimum purchase provisions are wide-spread; for example, Doucette (1997) notes that "a key characteristic of a successful GPO [group purchasing organisation] is its ability to obtain price concessions from suppliers, usually in exchange for some guaranteed minimum purchase volume by its members." By logical extension of the EC guidelines, minimum purchase provisions may be permitted by regulators as they may be perceived to be necessary to achieve economies of scale.

Before moving on to examine the stability of the buyer group arrangement in the presence of minimum purchase provisions, we determine the stability of a standard output market cartel. This will serve as a benchmark to which we compare the stability of the buyer group arrangement.

In the case of symmetric output market collusion, each retailer raises price to $p^{m}$ or restricts quantity to $q^{m}$, such that they jointly extract monopoly profits $\pi^{m}$, with each retailer earning $\pi^{m} / n$ per period. Given that all other retailers play the collusive strategy, retailer $i$ may deviate and earn single-period deviation profit $\pi^{d}$ by setting $q_{i}$ or $p_{i}$ to solve, respectively,

$$
\begin{aligned}
\pi^{d} & \equiv \max _{q_{i}} q_{i}\left(p\left(\frac{n-1}{n} Q^{m}+q_{i}\right)-c\right), \text { or } \\
\pi^{d} & \equiv \max _{p_{i}} q_{i}\left(p_{i}, \mathbf{p}_{-i}^{m}\right)\left(p_{i}-c\right) .
\end{aligned}
$$

Deviation is observed by rival retailers and induces grim trigger Nash punishment, resulting in retailers earning competitive profits $\pi^{c}$ in all future periods. Therefore, collusion is sustained if and only if the usual incentive compatibility constraint holds,

$$
\begin{aligned}
\sum_{t=1}^{\infty} \delta^{t-1} \frac{\pi^{m}}{n} & \geq \pi^{d}+\sum_{t=2}^{\infty} \delta^{t-1} \pi^{c} \\
\text { iff. } \delta & \geq \delta^{*}=\frac{\pi^{d}-\frac{\pi^{m}}{n}}{\pi^{d}-\pi^{c}} .
\end{aligned}
$$




\subsection{Minimum Purchase Clauses}

The stability of the buyer group arrangement depends on the temptation of retailers to cheat on their input market and to secretly negotiate additional wholesale contracts outside of the buyer group arrangement - just like the stability of standard output market collusion depends on the temptation to cheat on the output market and undercut rivals.

A retailer negotiating an additional unobservable contract outside of the buyer group arrangement, with a wholesale price lower than $w^{m}$, gains a competitive advantage over its rivals in the subsequent competition stage, because rivals are supplied at $w^{m}$. The optimal additional contract a deviant retailer negotiates prescribes a wholesale price equal to marginal cost,

$$
(w, \tau)=(c, 0)
$$

which allows the deviant retailer to price below $p^{m}$ or increase final output above $q^{m}$ in the competition stage.

Minimum purchase clauses oblige retailers to source a minimum quantity of inputs through the buyer group at wholesale price $w^{m}$, which makes secret negotiation of an additional contract outside of the buyer group arrangement less profitable. That is, the deviant retailer cannot buy its entire deviant quantity outside of the buyer group arrangement at the lower wholesale price $c$, but only the amount the deviant retailer produces on top of the amount dictated by the minimum purchase clause.

Such a deviation is detected by rival retailers through observing the competitive outcome on the output market. That is, they would observe that the deviant retailer produces more outputs, i.e. sources more inputs, than would be expected at wholesale price $w^{m}$.

Proposition 2 When contracts can specify minimum purchase provisions, the buyer group optimally negotiates contracts specifying $\left(w^{m}, \tau^{m}\right)$, as well as a minimum purchase clause of $q^{m}$. Retailers then jointly extract monopoly profits, and the buyer group arrangement is stable for the same set of discount factors for which standard output market collusion is stable,

$$
\delta_{b g}^{*}=\delta^{*}
$$

Proof. Denote by $\bar{q}$ the minimum purchase quantity. In the profit maximising equilibrium, each retailer produces $q^{m}$ and therefore the group strictly prefers to set $\bar{q} \leq q^{m}$. The optimal contract that a retailer is able to secretly negotiate outside of the buyer group arrangement is $(w, \tau)=(c, 0)$. 
Restricted by the quantity clause, the defecting retailer is obliged to source an amount $\bar{q}$ through the buyer group at marginal cost $w^{m}$, and can only source incremental amounts outside of the buyer group arrangement at marginal cost $c$. Therefore, noting that the deviating retailer will only produce $q_{i} \geq \bar{q}$, it sets $q_{i}$ or $p_{i}$ to solve, respectively,

$$
\begin{aligned}
& \pi_{b g}^{d}=\max _{q_{i}} q_{i} p\left(\frac{n-1}{n} Q^{m}+q_{i}\right)-\left(\bar{q} w^{m}+\left(q_{i}-\bar{q}\right) c\right)-\tau^{m}, \text { or } \\
& \pi_{b g}^{d}=\max _{p_{i}} q_{i}\left(p_{i}, \mathbf{p}_{-i}^{m}\right) p_{i}-\left(\bar{q} w^{m}+\left(q_{i}\left(p_{i}, \mathbf{p}_{-i}^{m}\right)-\bar{q}\right) c\right)-\tau^{m} .
\end{aligned}
$$

We have $\frac{\partial \pi_{b g}^{d}}{\partial \bar{q}}<0$, and therefore the optimal minimum purchase quantity is $\bar{q}=q^{m}$, which gives $\pi_{b g}^{d}=\pi^{d}$ by simplifying (4) and (5), because $\tau^{m}=-\left(w^{m}-c\right) q^{m}$. Again, the per-period profit earned by participating in the buyer group is $\pi^{m} / n$, while the profit decreases to $\pi^{c}$ in periods following defection. As a result, the buyer group induced monopoly outcome is stable if and only if

$$
\begin{aligned}
\frac{\pi^{m}}{(1-\delta) n} & \geq \pi^{d}+\frac{\delta \pi^{c}}{1-\delta} \\
\text { iff. } \delta & \geq \delta_{b g}^{*}=\frac{\pi^{d}-\frac{\Pi^{m}}{n}}{\pi^{d}-\pi^{c}}=\delta^{*} .
\end{aligned}
$$

The buyer group arrangement is now as stable as standard collusion, because the deviation profits are equal in both cases. The intuition is that the deviant retailer negotiates a contract outside of the group arrangement with a wholesale price of $c$, which is the same wholesale price a deviant retailer would face in the case of conventional collusion. As a result, the 'marginal condition' is equal in both cases, leading to the same deviation output or price. This in turn leads to the same deviation profits, since although the buyer group contract specifies a wholesale price $w^{m}>c$ on the first $q^{m}$ units, the difference is refunded through the slotting allowance and thus has no net effect on total deviation profits.

\subsection{No Additional Clauses}

Consider the case of simple two-part tariff contracts without the option to sign additional clauses. Again, we allow retailers to unobservably deviate from the buyer group by secretly signing additional wholesale contracts, and examine the stability of the arrangement. Such a deviation would be detected by rival retailers through observing the competitive outcome on the output market, because the deviant retailer produces more outputs, i.e. sources more inputs, than would be expected 
at wholesale price $w^{m}$. The following proposition states that, in such a case, the buyer group arrangement is less stable than standard output market collusion.

Proposition 3 Without the possibility of committing to vertical restraints, if retailers are patient enough, the buyer group induces the joint monopoly outcome through wholesale contracts specifying $\left(w^{m}, \tau^{m}\right)$. The buyer group arrangement is less stable than standard output market collusion,

$$
\delta_{b g}^{*}>\delta^{*}
$$

Proof. The per-period profit earned by participating in the buyer group is $\pi^{m} / n$, while the profit decreases to $\pi^{c}$ in periods following defection from the common arrangement. Because now the buyer group has no minimum purchase requirement, the deviating retailer sources all of his inputs through the supplier he secretly negotiated with instead of through the buyer group contract, because $c<w^{m}$. In case of quantity or price competition, the deviating retailer sets $q_{i}$ or $p_{i}$ so as to solve, respectively,

$$
\begin{aligned}
\pi_{b g}^{d} & =\max _{q_{i}} q_{i}\left(p\left(\frac{n-1}{n} Q^{m}+q_{i}\right)-c\right)-\tau^{m}, \text { or } \\
\pi_{b g}^{d} & =\max _{p_{i}} q_{i}\left(p_{i}, \mathbf{p}_{-i}^{m}\right)\left(p_{i}-c\right)-\tau^{m} .
\end{aligned}
$$

The retailer that secretly negotiated an additional contract effectively faces the same optimisation problem as a retailer that deviates from tacit collusion - compare for example (3) and (6). These equations are identical except for the slotting allowance term, that is, $\pi_{b g}^{d}=\pi^{d}-\tau^{m}$. The slotting allowance is fixed (sunk) and therefore has no impact on the optimal deviation strategy: a retailer deviating from the buyer group arrangement sets the same price or quantity as a retailer deviating from standard output market collusion. As a result, the buyer group is stable if and only if

$$
\begin{aligned}
\frac{\pi^{m}}{(1-\delta) n} & \geq \pi^{d}-\tau^{m}+\frac{\delta \pi^{c}}{1-\delta} \\
\quad \text { iff. } \delta & \geq \delta_{b g}^{*}=\frac{\pi^{d}-\tau^{m}-\frac{\pi^{m}}{n}}{\pi^{d}-\tau^{m}-\pi^{c}}>\delta^{*},
\end{aligned}
$$

because $\tau^{m}<0$ (the fixed fee is a slotting allowance).

The intuition for this result is that the deviant retailer not only earns an amount $\pi^{d}$ by sourcing through a different supplier; this retailer also receives the slotting allowance prescribed in the buyer group contract. In other words, sticking to the buyer group strategy gives a payoff equal to the conventional collusive payoff, while negotiating an additional contract outside of the buyer group 
arrangement gives the 'collusive deviating payoff' plus the slotting allowance. The temptation to deviate from the buyer group arrangement is thus higher than the temptation to deviate from conventional collusion.

Deviation by sourcing an amount $q^{d}$ outside of the buyer group arrangement is detected by rival retailers through observing the competitive outcome on the output market. Now consider the following type of deviation: the deviant retailer buys the amount $q^{m}$ at wholesale price $c$ outside of the buyer group arrangement. Again, the deviant retailer would increase its earnings, because it sources at price $c$ instead of $w^{m}$, while still receiving the slotting allowance $\tau^{m}$. Such a deviation would not be observable on the output market as the volume of outputs produced is $q^{m}$. However, deviating by sourcing amount $q^{m}$ through a different supplier is dominated by deviating by sourcing amount $q^{d}$, because (i) it is less profitable, because deviating with an amount $q^{m}$ gives a lower payoff than deviating with the optimal amount $q^{d}$, and (ii) it is still detected by other buyer group members since the deviant retailer does not source any inputs centrally through the buyer group. In the next section, we show that such a deviation is unprofitable altogether in the case of rebate schemes instead of slotting allowances.

\subsection{Rebate Schemes}

In the analysis so far, we have assumed that the payment of the (negative) fixed fee is not contingent on the volume of purchases. We now relax this assumption and allow for rebate schemes, i.e. payment of the fixed fee depends on the volume of inputs purchased. These rebates are paid retroactively after all inputs have been purchased. Let subscript ' $r s$ ' denote the case in which the buyer group contract allows for rebate schemes.

Proposition 4 When contracts can specify that the fixed fee can be paid as a rebate, the buyer group optimally negotiates contracts specifying $\left(w^{m}, \tau^{m}\right)$, where $\tau^{m}$ is paid if and only if the retailer sources at least $q^{m}$ units of inputs through the buyer group contract. Retailers then jointly extract monopoly profits, and the buyer group arrangement is stable for the same set of discount factors for which standard output market collusion is stable,

$$
\delta_{b g}^{*}=\delta^{*}
$$

Proof. The contract that allows retailers to extract joint monopoly profits on the output market is still $\left(w^{m}, \tau^{m}\right)$, while the optimal contract that a retailer is able to secretly negotiate outside of 
the buyer group arrangement is $(w, \tau)=(c, 0)$. Denote by $\bar{q}_{r s}$ the volume of inputs that must be purchased through the buyer group in order to receive the rebate $\tau^{m}$.

There are two ways for a buyer group member to deviate: (i) sourcing an amount $\bar{q}_{r s}$ against unit cost $w^{m}$ through the buyer group, thereby receiving the rebate $\tau^{m}$, while sourcing an amount $q_{i}-\bar{q}_{r s}$ outside of the buyer group against unit cost $c$, or (ii) sourcing the full amount $q_{i}$ outside of the buyer group against unit cost $c$ without receiving the rebate.

The first type of deviation gives deviating profit $\pi_{r s}^{d}=\pi_{b g}^{d}$ as in expressions (4) and (5) with $\bar{q}$ replaced by $\bar{q}_{r s}$. Noting that retailers strictly prefer $\bar{q}_{r s} \leq q^{m}$ (otherwise the rebate may incentivise retailers to produce more than the monopoly output), and that $\frac{\partial \pi_{r s}^{d}}{\partial \bar{q}_{r s}}<0$, we have that optimally the buyer group sets the rebate threshold at $\bar{q}_{r s}=q^{m}$. This then means that $\pi_{r s}^{d}=\pi^{d}$.

In the second type of deviation, the deviant retailer sets $q_{i}$ or $p_{i}$ to solve, respectively,

$$
\begin{aligned}
& \pi_{b g}^{d}=\max _{q_{i}} q_{i} p\left(\frac{n-1}{n} Q^{m}+q_{i}\right)-q_{i} c, \text { or } \\
& \pi_{b g}^{d}=\max _{p_{i}} q_{i}\left(p_{i}, \mathbf{p}_{-i}^{m}\right) p_{i}-q_{i}\left(p_{i}, \mathbf{p}_{-i}^{m}\right) c,
\end{aligned}
$$

which is equivalent to equations (3). Therefore, we again have that $\pi_{r s}^{d}=\pi^{d}$. Thus, both types of deviation give the same deviating profit.

Since the per-period profit earned by participating in the buyer group is $\pi^{m} / n$, while the profit decreases to $\pi^{c}$ in periods following defection, the buyer group induced monopoly outcome is stable if and only if

$$
\delta \geq \quad \delta_{b g}^{*}=\frac{\pi^{d}-\frac{\Pi^{m}}{n}}{\pi^{d}-\pi^{c}}=\delta^{*}
$$

Thus, rebate schemes - instead of slotting allowances - in the input market also allow retailers to achieve the monopoly outcome in the output market. The difference between rebates and slotting allowances is that rebates are paid after the purchase of inputs (conditionally dependent of the purchased volume), while slotting allowances are paid before the purchase of inputs (independent of the purchased volume). Now, deviating can take two forms: (i) sourcing just enough inputs through the buyer group so as to receive the rebate, while sourcing the remaining inputs outside of the buyer group at lower input cost $c$, or (ii) sourcing the entire deviating quantity outside of the buyer group.

Since the optimal rebate threshold is $q^{m}$, the first type of deviation entails the same deviating payoff as with minimum purchase clauses, from which we already know that its stability is the same 
as that of a standard output market cartel. With the second type of deviation, the deviant retailer sources all of its inputs outside of the buyer group arrangement at unit cost $c$ without receiving the rebate, which also gives the same deviating payoff as that of a standard output cartel. Hence, rebate schemes allows the stability of the anticompetitive buyer group to be restored to $\delta^{*}$.

Note that the type of deviation discussed in the last paragraph of the previous subsection is unprofitable with rebate schemes. That is, deviating by sourcing $q^{m}$ outside of the buyer group at wholesale price $c$ results in the rebate $\tau^{m}$ not being paid out. Thus, deviation gives the same profit in the current (deviation) period as sticking to the equilibrium strategy, i.e. $q^{m}\left(p^{m}-c\right)=\frac{\pi^{m}}{n}$, while resulting in Nash punishment in future periods.

\subsection{Buyer Group Specific Cost Savings: Stability and Welfare}

So far, we have assumed that there are no monetary benefits from centrally sourcing through the buyer group. However, buyer group specific cost savings-(possibly) caused by central sourcingare an important rationale for forming a buyer group. ${ }^{16}$ Such cost savings not only affect the buyer group's stability, but also has implications for (consumer) welfare. ${ }^{17}$

Suppose the buyer group generates efficiencies in marginal cost, such as a reduction in the variable part of transportation or transaction costs, or more generally, savings through bulk ordering and scale economies. These cost efficiencies would increase the buyer group's stability for two reasons. First, defection becomes relatively less profitable, because the deviant retailer does not enjoy cost savings when sourcing from a supplier outside of the buyer group arrangement. Second, Nash punishment after defection is relatively fiercer, because no cost efficiencies are realised during punishment. The larger the cost savings, the larger are these two effects. As a result, the buyer group becomes more stable as cost savings are larger, and becomes stable against cheating for all discount factors if cost savings are sufficiently large.

Retailers always benefit from establishing a buyer group, because they profit from both the "cartelization effect" and the "cost savings effect". Whether consumers also benefit from the buyer group, and by how much, depends on the relative importance of the pass-through of cost efficiencies compared to the anticompetitive "cartelization effect". While collusion tends to increase price (or: reduce output), cost savings tend to increase price (or: reduce output). Consumers, thus, benefit

\footnotetext{
${ }^{16}$ For example, the Floral Buyer Group claims to realise cost savings through more efficient transportation and storage of flowers, while the Aidelade Buyers Group saves on overheads by jointly purchasing power components.

${ }^{17}$ We describe the driving forces qualitatively; a technical exposition of the arguments in the Cournot model with linear demand is available online at carteltheory.com/buyergroupefficiencies.
} 
from the anticompetitive buyer group if and only if the pass-on of cost savings outweighs the collusion effect. Therefore, a buyer group that serves to extract cartel rents on the output market may actually be welfare-enhancing for consumers compared to the fully competitive benchmark. ${ }^{18}$

\section{$5 \quad$ Policy Implications and Concluding Remarks}

Buyer groups play an important role across a wide range of sectors in the economy. They may facilitate pro-competitive forces based on buyer power considerations, acting to reduce wholesale prices and level the playing field between smaller firms and larger firms that can exercise buyer power unilaterally, which is potentially to the benefit of final consumers. We instead develop a model of a strictly anticompetitive effect of buyer groups in markets where wholesale contracting is unobservable. A buyer group allows its members to credibly commit to wholesale contracts that induce joint monopoly profits in the downstream market. We show that commonly observed vertical restraints and contracting terms - exclusivity provisions, minimum purchase clauses, and rebate schemes - enhance the stability of the buyer group by effectively limiting retailers' ability or incentives to defect from the arrangement.

Our findings contribute to the growing debate both among academics and practitioners on the competitive effects of buyer groups, and what the appropriate approach by regulators should be to dealing with such arrangements, which are not per se illegal under either US antitrust law or EU competition law. This discussion has traditionally mirrored that which surrounds the issue of buyer power more generally. By enabling firms to exercise countervailing power over their suppliers, a buyer group can allow its members to obtain lower input prices, a significant proportion of which may be passed onto consumers in the form of lower retail prices, provided that there is effective retail competition (Inderst and Mazzarotto, 2007). On the other hand, it has been argued that the exercise of buyer power could potentially result in waterbed effects, resulting in rival buyers being charged higher prices or being offered inferior quality inputs (Majumdar, 2006, Inderst and Valletti, 2009).

Furthermore, buyer groups can potentially serve to level the playing field between firms downstream, by allowing smaller buyers access to the same terms of trade that larger buyers have access to. Finally, and of most relevance to our findings, buyers groups can have implications for the

\footnotetext{
${ }^{18}$ Reductions in fixed costs would also increase the buyer group's stability by the two reasons mentioned above. Consumer welfare would be unaltered, however, as fixed costs are sunk and do not affect the retailers' behavior on the output market. See the last paragraph of Section 5 for more discussion.
} 
potential for tacit collusion between members. For example, the group arrangement may result in the sharing of information between firms or may serve to increase the degree of symmetry between members, thereby possibly facilitating collusion (see UK Office of Fair Trading, 2007).

Our findings have highlighted additional factors that policy makers must be aware of when dealing with buyer groups. If buyer groups act as 'implied cartels', they may be mistakenly identified as pro-competitive forces, with retailers arguing that a buyer group allows them to secure discounts from suppliers, which can then be passed on to consumers in the form of lower prices. In our model, retailers may use the high slotting allowances paid by the suppliers in equilibrium as 'evidence' of the buyer group being a pro-competitive organisation acting to reduce input prices. We therefore caution policy makers assessing the impact of a buyer group to be careful when interpreting evidence on input prices, and to recognise that high slotting fees will likely not result in enhanced downstream competition (as they are fixed payments) and that they may be paid in response to higher wholesale prices, which explicitly reduce downstream competition.

A further key issue for policy makers which our conclusions highlight relates to the fact that an anticompetitive buyer group is likely to be harder to detect than standard forms of output market collusion, such as (tacitly) raising prices. An antitrust authority investigating the output market may not be able to find evidence of anticompetitive behaviour if the retailers use a buyer group to jointly expropriate monopoly profits. An analysis of, for example, price-cost mark-ups would find no evidence of firms pricing above competitive levels if the retailers' costs are taken as given. It may be a significant step for the antitrust authority to expand the analysis of suspected retailer collusion to include an examination of the process of wholesale contracting between retailers and suppliers in the upstream market, but our work highlights that this may indeed be necessary. ${ }^{19}$

Our work also contributes to the continuing policy debate regarding vertical restraints. Interestingly, in our model such restraints are not imposed on buyers by powerful suppliers in order to extract profits or exclude upstream rivals, but are willingly entered into by retailers themselves as a means by which they can jointly credibly commit to purchasing from the buyer group at higher wholesale prices. Our findings therefore caution against possible anti-competitive effects when vertical restraints are observed in such circumstances. In the model, we explicitly considered exclusive dealing and minimum purchase clauses, as well as rebate schemes, but similar results would be ob-

\footnotetext{
${ }^{19}$ For example, the EC imposed fines on five firms active in the Spanish raw tobacco industry as it concluded that purchasing quotas were effectively targets for market shares in the downstream market (Case COMP/C.38.238/B.2 Raw Tobacco Spain, 2004).
} 
tained through the use of retail price maintenance (RPM). Then, retailers could coordinate their wholesale contracts to include RPM clauses that prevent them from pricing below the monopoly price on the output market.

Similar effects may be expected to arise from other restraints which serve to encourage buyers to purchase from a single supplier, such as input joint ventures and franchising. As for joint ventures, Priest (1977) and Chen and Ross (2003) show that an industry-wide joint venture, where its members are charged per-unit royalties, functions similarly as a buyer group with slotting allowances. The joint venture may set per-unit royalties on the input market high enough such that the monopoly outcome is realised on the output market, while sharing the joint venture's profit among the retailers, resulting in joint monopoly profits being realised. Also, franchising is often organised as a buyer group (Blair and Lafontaine, 2005), allowing for the same anticompetitive effects as an implied cartel'.

However, we also note that even when the cartelization effect we identify is present, it cannot be interpreted in isolation from all of the other issues which surround buyer groups. We demonstrated that even when a buyer group serves to expropriate joint monopoly profits on the output market, consumers can still be better off when this effect is outweighed by efficiency savings which then actually result in lower retail prices. Therefore, the effect we identify must be considered alongside other evidence on how such groups affect the relationship between buyers and sellers, and competition in the downstream market.

As well as demonstrating that buyer groups can potentially facilitate explicit collusion, our work also serves to highlight the conditions under which this is likely to be a concern. Primarily, in exchange for the higher wholesale prices that buyers pay they must receive lump sum slotting fees in return, otherwise it would be the suppliers that expropriated the monopoly rents and the buyers would actually be worse off. In practice, this need not be an explicit 'slotting fee', but could for example be presented as a 'marketing allowance' or an end of year rebate; and in principle it does not even need to be an explicit monetary payment; for example, the supplier could pass on technological knowhow or superior training methods of equal value. Secondly, an anticompetitive buyer group arrangement is much more likely to successfully arise when the membership of the group in question consists of all of the firms in the market. If many firms remain outside of the group, they would likely be able to undercut the higher retail prices offered by the group members (or increase output to make up for their restriction), and would therefore deter the group from attempting to undertake such a cost-raising arrangement in the first place. 
As a final note, we argued in Section 4.4 that efficiencies in marginal costs generated through the buyer group increase its stability, and may even benefit consumers. Other advantages of buyer groups, such as a reduction in fixed costs or the exercise of buyer power, would similarly stabilise the anticompetitive mechanism. The impact on consumers and welfare would again depend on the nature and pass-through of those advantages to consumers. For example, if the exercise of buyer power leads to increased product quality, consumers benefit in the sense that they consume a superior product than they otherwise would. On the other hand, while a buyer group specific reduction in fixed costs would increase the group's stability, consumers would in no way benefit since fixed costs do not affect the competitive outcome in the output market. Thus, the welfare effects of an anticompetitive buyer group critically depend on the type of efficiencies created, and how these tradeoff against the cartelization effect. However, although buyer groups may generate efficiencies that are to the benefit of final consumers, our work indicates that exclusive dealing and minimum purchase contracts negotiated through buyer groups, in combination with slotting allowances, or the use of rebate schemes, may be worthy of closer scrutiny by regulators. 


\section{References}

[1] Abito, J.M. and Wright, J. (2008), Exclusive Dealing with Imperfect Downstream Competition, International Journal of Industrial Organization 26, 227-246.

[2] Aghion, P. and Bolton, P. (1987), Contracts as a Barrier to Entry, American Economic Review $77,388-401$.

[3] Bernheim, B.D and Whinston, M.D. (1998), Exclusive Dealing, Journal of Political Economy 106, 64-103.

[4] Blair, R.D. and Lafontaine, F. (2005), The Economics of Franchising, Cambridge University Press, New York.

[5] Chae, S. and Heidhues, P. (2004), Buyers' Alliances for Bargaining Power, Journal of Economics Es Management Strategy 13, 731-754.

[6] Che, Y. and Gale, I. (2004), Buyer Alliances and Managed Competition, Journal of Economics \& Management Strategy 6, 175-200.

[7] Chen, Z. and Ross, T.W. (2003), Cooperating Upstream While Competing Downstream: a Theory of Input Joint Ventures, International Journal of Industrial Organization 21, 381-397.

[8] Dana, J. (2003), Buyer Groups as Strategic Commitments, mimeo.

[9] Dobson, P.W., and Waterson, M. (1997), Countervailing Power and Consumer Prices, The Economic Journal 107, 418-430.

[10] Dobson, P.W. and Waterson, M. (1999), Retailer Power: Recent Developments and Policy Implications, Economic Policy, 135-164.

[11] Doucette, W.R. (1997), Influences on Member Commitment to Group Purchasing Organizations, Journal of Business Research 40, 183-189.

[12] European Commission (2001), Guidelines on the Applicability of Article 81 of the EC Treaty to Horizontal Cooperation Agreements, Official Journal of the European Commission, 2001/C, $3 / 02-3 / 30$.

[13] Federal Trade Commission (2003), Slotting Allowances in the Retail Grocery Industry: Selected Case Studies in Five Product Categories.

[14] Fershtman, C. and Judd, K.L. (1987), Equilibrium Incentives in Oligopoly, American Economic Review 77, 927-940. 
[15] Fumagalli, C. and M. Motta (2006), American Economic Review 96, 785-795.

[16] Foros, Ø. and Kind, H.J. (2008), Do Slotting Allowances Harm Retail Competition?, Scandinavian Journal of Economics 110, 367-384.

[17] Foros, Ø., Kind, H.J. and Sand, J.Y. (2009), Slotting Allowances and Manufacturers' Retail Sales Effort, Southern Economic Journal 76, 266-282.

[18] Inderst, R. (2007), Single Sourcing vs. Multiple Sourcing, RAND Journal of Economics 39, 199-213.

[19] Inderst, R. and Mazzarotto, N. (2007), Buyer Power in Distribution, chapter for the ABA Antitrust Section Handbook, Issues in Competition Law and Policy (W.D. Collins, ed.).

[20] Inderst, R. and Shaffer, G. (2007), The Role of Buyer Power in Merger Control, chapter for the ABA Antitrust Section Handbook, Issues in Competition Law and Policy (W.D. Collins, ed.).

[21] Inderst, R. and Valletti, T. (2009), Buyer Power and the "Waterbed Effect", Journal of Industrial Economics, forthcoming.

[22] Inderst, R. and Wey, C. (2003), Bargaining, Mergers, and Technology Choice in Bilaterally Oligopolistic Industries, RAND Journal of Economics 34, 1-19.

[23] Inderst, R. and Wey, C. (2007), Buyer Power and Supplier Incentives, European Economic Review 51, 647-667.

[24] Irmen, A. (1998), Precommitment in Competing Vertical Restraints, Journal of Economic Surveys 12, 333-359.

[25] Katz, M.L. (1987), The Welfare Effects of Third-Degree Price Discrimination in Intermediate Good Markets, The American Economic Review 77, 154-167.

[26] Katz, M.L. (1991), Game-Playing Agents: Unobservable Contracts as Precommitments, RAND Journal of Economics 22, 307-328.

[27] Majumdar, A. (2006), Waterbed Effects, 'Gatekeepers' and Buyer Mergers, CCP Working Paper No 05-7.

[28] Marvel, H.P and Yang, H. (2008), Group Purchasing, Nonlinear Tariffs and Oligopoly, International Journal of Industrial Organization 26, 1090-1105.

[29] Marx, L.M. and Shaffer, G. (2007), Upfront Payments and Exclusion in Downstream Markets, RAND Journal of Economics 38, 823-843 
[30] Mathewson, F. and Winter, R.A. (1996), Buyer Groups, International Journal of Industrial Organization 15, 137-164.

[31] Miklós-Thal, J., Rey, P. and Vergé, T. (2011), Buyer Power and Intrabrand Coordination, Journal of the European Economic Association 9, 721-741.

[32] Nordemann, J.B. (1995), Buying Power and Sophisticated Buyers in Merger Control Law: the Need for a More Sophisticated Approach, European Competition Law Review 5, 270-281.

[33] Office of Fair Trading, UK (2007), The Competitive Effects of Buyer Groups, Economic Discussion Paper, A Report Prepared for the OFT by RBB Economics.

[34] OECD (1998), Buying Power of Multiproduct Retailers, Policy Roundtables.

[35] Piccolo, S. (2010), Colluding Through Suppliers, CSEF Working Paper No. 224.

[36] Priest, G.L. (1977), Cartels and Patent License Agreements, Journal of Law 83 Economics 20, 309-377.

[37] Rasmusen, E.B., Ramseyer, J.M. and Wiley, J.S. (1991), Naked Exclusion, American Economic Review 81, 1137-1145.

[38] Rey, P. and Stiglitz, J. (1995), The Role of Exclusive Territories in Producer's Competition, RAND Journal of Economics 26, 431-451.

[39] Segal, I. and Whinston, M.D. (2000), Naked Exclusion: Comment, American Economic Review 90, 296-309.

[40] Shaffer, G. (1991), Slotting Allowances and Retail Price Maintenance: A Comparison of Facilitating Practices, RAND Journal of Economics 22, 120-135.

[41] Shaffer, G. (1992) and O'Brien, D.P. (1992), Vertical Control With Bilateral Contracts, RAND Journal of Economics 23, 299-308.

[42] Simpson, J. and Wickelgren, A.L. (2007), Naked Exclusion, Efficient Breach, and Downstream Competition, American Economic Review 97, 1305-1320.

[43] Sklivas, S.D. (1987), The Strategic Choice of Managerial Incentives, RAND Journal of Economics $18,452-458$.

[44] Snyder, C. M. (1996), A Dynamic Theory of Countervailing Power, RAND Journal of Economics $27,747-769$.

[45] Snyder, C. M. (1998), Why Do Larger Buyers Pay Lower Prices? Intense Supplier Competition, Economics Letters 58, 205-209. 


\section{SFB 649 Discussion Paper Series 2012}

For a complete list of Discussion Papers published by the SFB 649, please visit http://sfb649.wiwi.hu-berlin.de.

001 "HMM in dynamic HAC models" by Wolfgang Karl Härdle, Ostap Okhrin and Weining Wang, January 2012.

002 "Dynamic Activity Analysis Model Based Win-Win Development Forecasting Under the Environmental Regulation in China" by Shiyi Chen and Wolfgang Karl Härdle, January 2012.

003 "A Donsker Theorem for Lévy Measures" by Richard Nickl and Markus Reiß, January 2012.

004 "Computational Statistics (Journal)" by Wolfgang Karl Härdle, Yuichi Mori and Jürgen Symanzik, January 2012.

005 "Implementing quotas in university admissions: An experimental analysis" by Sebastian Braun, Nadja Dwenger, Dorothea Kübler and Alexander Westkamp, January 2012.

006 "Quantile Regression in Risk Calibration" by Shih-Kang Chao, Wolfgang Karl Härdle and Weining Wang, January 2012.

007 "Total Work and Gender: Facts and Possible Explanations" by Michael Burda, Daniel S. Hamermesh and Philippe Weil, February 2012.

008 "Does Basel II Pillar 3 Risk Exposure Data help to Identify Risky Banks?" by Ralf Sabiwalsky, February 2012.

009 "Comparability Effects of Mandatory IFRS Adoption" by Stefano Cascino and Joachim Gassen, February 2012.

010 "Fair Value Reclassifications of Financial Assets during the Financial Crisis" by Jannis Bischof, Ulf Brüggemann and Holger Daske, February 2012.

011 "Intended and unintended consequences of mandatory IFRS adoption: A review of extant evidence and suggestions for future research" by Ulf Brüggemann, Jörg-Markus Hitz and Thorsten Sellhorn, February 2012.

012 "Confidence sets in nonparametric calibration of exponential Lévy models" by Jakob Söhl, February 2012.

013 "The Polarization of Employment in German Local Labor Markets" by Charlotte Senftleben and Hanna Wielandt, February 2012.

014 "On the Dark Side of the Market: Identifying and Analyzing Hidden Order Placements" by Nikolaus Hautsch and Ruihong Huang, February 2012.

015 "Existence and Uniqueness of Perturbation Solutions to DSGE Models" by Hong Lan and Alexander Meyer-Gohde, February 2012.

016 "Nonparametric adaptive estimation of linear functionals for low frequency observed Lévy processes" by Johanna Kappus, February 2012.

017 "Option calibration of exponential Lévy models: Implementation and empirical results" by Jakob Söhl und Mathias Trabs, February 2012.

018 "Managerial Overconfidence and Corporate Risk Management" by Tim R. Adam, Chitru S. Fernando and Evgenia Golubeva, February 2012.

019 "Why Do Firms Engage in Selective Hedging?" by Tim R. Adam, Chitru S. Fernando and Jesus M. Salas, February 2012.

020 "A Slab in the Face: Building Quality and Neighborhood Effects" by Rainer Schulz and Martin Wersing, February 2012.

021 "A Strategy Perspective on the Performance Relevance of the CFO" by Andreas Venus and Andreas Engelen, February 2012.

022 "Assessing the Anchoring of Inflation Expectations" by Till Strohsal and Lars Winkelmann, February 2012.

\section{SFB 649, Spandauer Straße 1, D-10178 Berlin http:/ / sfb649.wiwi.hu-berlin.de}

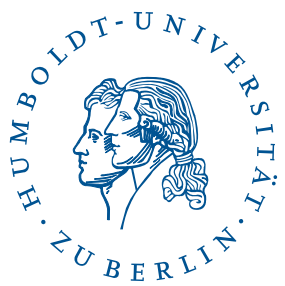




\title{
SFB 649 Discussion Paper Series 2012
}

For a complete list of Discussion Papers published by the SFB 649, please visit http://sfb649.wiwi.hu-berlin.de.

023 "Hidden Liquidity: Determinants and Impact" by Gökhan Cebiroglu and Ulrich Horst, March 2012.

024 "Bye Bye, G.I. - The Impact of the U.S. Military Drawdown on Local German Labor Markets" by Jan Peter aus dem Moore and Alexandra Spitz-Oener, March 2012.

025 "Is socially responsible investing just screening? Evidence from mutual funds" by Markus Hirschberger, Ralph E. Steuer, Sebastian Utz and Maximilian Wimmer, March 2012.

026 "Explaining regional unemployment differences in Germany: a spatial panel data analysis" by Franziska Lottmann, March 2012.

027 "Forecast based Pricing of Weather Derivatives" by Wolfgang Karl Härdle, Brenda López-Cabrera and Matthias Ritter, March 2012.

028 "Does umbrella branding really work? Investigating cross-category brand loyalty" by Nadja Silberhorn and Lutz Hildebrandt, April 2012.

029 "Statistical Modelling of Temperature Risk" by Zografia Anastasiadou, and Brenda López-Cabrera, April 2012.

030 "Support Vector Machines with Evolutionary Feature Selection for Default Prediction" by Wolfgang Karl Härdle, Dedy Dwi Prastyo and Christian Hafner, April 2012.

031 "Local Adaptive Multiplicative Error Models for High-Frequency Forecasts" by Wolfgang Karl Härdle, Nikolaus Hautsch and Andrija Mihoci, April 2012.

032 "Copula Dynamics in CDOs." by Barbara Choroś-Tomczyk, Wolfgang Karl Härdle and Ludger Overbeck, May 2012.

033 "Simultaneous Statistical Inference in Dynamic Factor Models" by Thorsten Dickhaus, May 2012.

034 "Realized Copula" by Matthias R. Fengler and Ostap Okhrin, Mai 2012.

035 "Correlated Trades and Herd Behavior in the Stock Market" by Simon Jurkatis, Stephanie Kremer and Dieter Nautz, May 2012

036 "Hierarchical Archimedean Copulae: The HAC Package" by Ostap Okhrin and Alexander Ristig, May 2012.

037 "Do Japanese Stock Prices Reflect Macro Fundamentals?" by Wenjuan Chen and Anton Velinov, May 2012.

038 "The Aging Investor: Insights from Neuroeconomics" by Peter N. C. Mohr and Hauke R. Heekeren, May 2012.

039 "Volatility of price indices for heterogeneous goods" by Fabian Y.R.P. Bocart and Christian M. Hafner, May 2012.

040 "Location, location, location: Extracting location value from house prices" by Jens Kolbe, Rainer Schulz, Martin Wersing and Axel Werwatz, May 2012.

041 "Multiple point hypothesis test problems and effective numbers of tests" by Thorsten Dickhaus and Jens Stange, June 2012

042 "Generated Covariates in Nonparametric Estimation: A Short Review." by Enno Mammen, Christoph Rothe, and Melanie Schienle, June 2012.

043 "The Signal of Volatility" by Till Strohsal and Enzo Weber, June 2012.

044 "Copula-Based Dynamic Conditional Correlation Multiplicative Error Processes" by Taras Bodnar and Nikolaus Hautsch, July 2012

\author{
SFB 649, Spandauer Straße 1, D-10178 Berlin \\ http:/ / sfb649.wiwi.hu-berlin.de
}




\section{SFB 649 Discussion Paper Series 2012}

For a complete list of Discussion Papers published by the SFB 649, please visit http://sfb649.wiwi.hu-berlin.de.

045 "Additive Models: Extensions and Related Models." by Enno Mammen, Byeong U. Park and Melanie Schienle, July 2012.

046 "A uniform central limit theorem and efficiency for deconvolution estimators" by Jakob Söhl and Mathias Trabs, July 2012

047 "Nonparametric Kernel Density Estimation Near the Boundary" by Peter Malec and Melanie Schienle, August 2012

048 "Yield Curve Modeling and Forecasting using Semiparametric Factor Dynamics" by Wolfgang Karl Härdle and Piotr Majer, August 2012

049 "Simultaneous test procedures in terms of p-value copulae" by Thorsten Dickhaus and Jakob Gierl, August 2012

050 "Do Natural Resource Sectors Rely Less on External Finance than Manufacturing Sectors? " by Christian Hattendorff, August 2012

051 "Using transfer entropy to measure information flows between financial markets" by Thomas Dimpfl and Franziska J. Peter, August 2012

052 "Rethinking stock market integration: Globalization, valuation and convergence" by Pui Sun Tam and Pui I Tam, August 2012

053 "Financial Network Systemic Risk Contributions" by Nikolaus Hautsch, Julia Schaumburg and Melanie Schienle, August 2012

054 "Modeling Time-Varying Dependencies between Positive-Valued HighFrequency Time Series" by Nikolaus Hautsch, Ostap Okhrin and Alexander Ristig, September 2012

055 "Consumer Standards as a Strategic Device to Mitigate Ratchet Effects in Dynamic Regulation" by Raffaele Fiocco and Roland Strausz, September 2012

056 "Strategic Delegation Improves Cartel Stability" by Martijn A. Han, October 2012

057 "Short-Term Managerial Contracts and Cartels" by Martijn A. Han, October 2012

058 "Private and Public Control of Management" by Charles Angelucci and Martijn A. Han, October 2012

059 "Cartelization Through Buyer Groups" by Chris Doyle and Martijn A. Han, October 2012 